\title{
BIST 100 Endeksindeki Şirketlerin Sürdürülebilirlik Raporlarının Sektörler Açısından İncelenmesi
}

\author{
Analysis of the Sustainability Reports of the Companies in the BIST 100 Index in \\ Terms of Sectors
}

Harun $\ddot{O} \breve{G} \ddot{U} N C ̧ *$

$\ddot{O} Z$

Sürdürülebilirlik raporları işletmelerin ekonomik, sosyal ve çevresel konulardaki etkinliği ve hassasiyetini ortaya koyma aracı olarak karşımıza çıkmaktadır. Çevre muhasebesine ilişkin raporlamadan farklı olarak finansal olmayan ve çevre dışındaki konuları da içeren bu raporların hazırlanmasında GRI standartları önemli oranda kabul görmüş bulunmaktadır. Bu çalışmada BIST 100 endeksindeki şirketler tarafindan sürdürülebilirlik raporlarının ne ölçüde yayınlandığl, hangi maddelere yer verildiği, GRI maddeleri ve GRI kategorilerinin sayısının sektörlere göre farklılık gösterme durumu araştırlmıştır. Elde edilen bulgulara göre BIST 100 endeksindeki 46 şirketin sürdürülebilirlik raporu yayınladı̆̆ tespit edilmiştir. Ayrıca sektörlere göre GRI madde sayısının farklılık göstermediği; ancak GRI kategori sayılarının anlamlı düzeyde farklılık gösterdiği belirlenmiştir.

ANAHTAR KELIMELER

Sürdürülebilirlik, Çevre Muhasebesi, GRI Standartları

\begin{abstract}
Sustainability reports emerge as a means of demonstrating the efficiency and sensitivity of enterprises in economic, social and environmental issues. Unlike reporting on environmental accounting, GRI standards have been widely accepted in the preparation of these reports, which include non-financial and non-environmental issues. In this study, the extent to which sustainability reports are published by companies in the BIST 100 index, which items are included, and the differences in the number of GRI items and GRI categories by sectors were investigated. According to the findings obtained, it was determined that 46 companies in the BIST 100 index published sustainability reports. Also, the number of GRI items does not differ according to the sectors; however, it was determined that the numbers of GRI categories differ significantly.
\end{abstract}

KEYWORDS

Sustainability, Environmental Accounting, GRI Standards

\begin{tabular}{|c|c|c|}
\hline \multicolumn{2}{|r|}{$\begin{array}{c}\text { Makale Geliş Tarihi / Submission Date } \\
\text { 16.03.2021 }\end{array}$} & $\begin{array}{c}\text { Makale Kabul Tarihi / Date of Acceptance } \\
02.09 .2021\end{array}$ \\
\hline Atıf & $\begin{array}{l}\text { Öğünç, H. (2021). BİST } 100 \text { Endeksind } \\
\text { Selçu Üniversitesi Sosyal Bilimler Me }\end{array}$ & $\begin{array}{l}\text { lebilirlik Raporlarının Sektörler Açısından İncelenmesi. } \\
\text { isi, } 24 \text { (2), 340-351. }\end{array}$ \\
\hline
\end{tabular}

\footnotetext{
* Dr.Öğr.Üyesi, Burdur Mehmet Akif Ersoy Üniversitesi Bucak Zeliha Tolunay Uygulamalı Teknoloji ve İşletmecilik Yüksekokulu, harunogunc@hotmail.com, ORCID: 0000-0002-7349-0739
} 


\section{GÍRİŞ}

Muhasebenin temel kavramlarından biri olan "işletmenin sürekliliği”" kavramı, işletmelerin sınırsız bir ömre sahip olarak kurulduklarını veya belirli bir süreye bağlı olmaksızın faaliyetlerini sürdüreceklerini ifade etmektedir. İşletmelerin oldukça uzun bir süre faaliyetlerini devam ettireceği göz önünde bulundurulduğunda işletmenin içinde bulunduğu doğal çevrenin de uzun bir ömre sahip olması gerektiği gerçeği unutulmamalıdır. Çünkü hammadde ve enerjide devamlılık sağlanamadığında üretim veya satış da mümkün olmayacaktır. Ama sadece çevrenin işletmeye sağladığı hammadde, enerji gibi kaynaklar açısından konuyu değerlendirmek, eksik bir yaklaşım olacağı için tedarikçi ve müşteri başta olmak üzere toplumun birçok kesiminin dikkate alınması gerekmektedir. Çünkü sadece işletme gelirleri açısından düşünüldügünde bile çevreye duyarlı bir yaklaşım sergilemeyen işletmenin ürünlerine yönelik talepte bir azalış söz konusu olacaktır. Ayrıca sürdürülebilirlik raporları incelendiğinde birçok işletmenin sadece kendi faaliyetlerinde değil tedarikçilerin faaliyetlerinde de sürdürülebilirlik konularına önem verilmesini bekledikleri ve bunu söz konusu raporlarda beyan ettikleri görülmektedir.

Sürdürülebilirlik raporlarının hazırlanmasında yaygın bir şekilde kullanılan GRI (Global Reporting Initiative-Küresel Raporlama Girişimi) standartları, işletmelerin sunmuş olduğu raporlarda bu standartlarda bulunan konulara ne ölçüde yer verildiğini, dolayısıyla işletmenin bu standartlara ne ölçüde uygun bir faaliyet sürdürdüğünü raporlamayı amaçlamaktadır. İşletmeler faaliyetlerini sürdürürken genellikle finansal raporları yasal bir zorunluluk nedeniyle yayınlarken finansal olmayan raporları bir zorunluluk olmaksızın, işletmeyi farklı bir yerde konumlandırma amacı güderek yayınlamaktadırlar. Sürdürülebilirlik raporları da finansal olmayan raporlardan biri olarak karşımıza çıkmaktadır. Bunun yanında çevrede ortaya çıkan olumsuzlukların önemli bir öznesi konumundaki işletmelerin çevreye verdiği bu olumsuz katkıyı finansal raporlarında gösterebilmesi amacıyla çevre muhasebesi kavramı giderek daha fazla dikkat çeker duruma gelmiştir.

Çevre muhasebesi, çevre ile işletme arasında ortaya çıkan etkileşim sonucunda çevresel kaynakların kullanım biçiminin ve işletme faaliyetleri sonucunda bu kaynaklarda meydana gelen artış veya azalışın tespit edilmesi, ayrıca çevrede meydana gelen olumsuzlukların belirlenmesi, fiziksel ve parasal değerlerinin hesaplanarak izlenmesi ve raporlanması olarak ifade edilebilir (Özçelik, 2018: 40). Dolayısıyla çevre muhasebesi, çevresel sonuçların finansal raporlarda gösterilmesini hedefleyen bir yapıya sahiptir.

Çevre muhasebesi kavramının 1970'li yıllarda çevre sorunlarının daha dikkat çekici bir duruma gelmesiyle birlikte bu sorunların çözümüne katkı sağlamak amacıyla ortaya atıldığı görülmektedir. Gerek işletmelerin kendi çabası gerekse müşterilerin (veya genel olarak halkın) baskıları sonucunda işletmeler çevresel verileri paylaşma eğilimine girmiştir (A ̆g ve Güler Sülük, 2019: 1948).

Bu çalışmada çevre muhasebesiyle ilişkili olan; ancak finansal bir nitelik taşımayan sürdürülebilirlik raporlarındaki çevresel sorumluluklar incelenmiştir. Bu kapsamda Borsa İstanbul (BİST) 100 endeksinde yer alan ve internet sayfalarında sürdürülebilirlik raporu yayınlayan şirketlerin sürdürülebilirlik raporlarında GRI maddelerine ne ölçüde yer verdikleri incelenmiştir. Ayrıca raporlanan GRI madde sayısının sektörlere göre farklılık gösterme durumunun belirlenmesi amacıyla ANOVA; GRI kategori sayılarının sektörlere göre farklılık durumunun belirlenmesi amacıyla ise Kruskal Wallis H testi uygulanmıştır.

\section{SÜRDÜRÜLEBİLİRLİK RAPORU}

Sürdürülebilirlik raporları başlangıçta gönüllü bir hareket olarak başlayıp giderek artan önemi sebebiyle işletmeler ve kamuoyu tarafından hızla kabul görmüştür. İşletmeler sürdürülebilirlik raporu düzenleyerek ekonomik, çevresel, sosyal ve kurumsal yönetim başarısını kamuoyu ile paylaşmakta; bunun sonucunda ise kurumsal itibarında ve işletmeye duyulan güvende artışla birlikte marka imajını güçlendirmeye çalışmaktadır (Özerhan ve Sultanoğlu, 2018: 56). Dolayısıyla kurumsal yönetim başarısını bir sonuç olarak değerlendirdiğimizde sürdürülebilirliğin üç temel boyutu olduğu görülmektedir (Gould, 2011: 19):

- Ekonomik uygulanabilirlik

- Sosyal sorumluluk

- Çevresel sorumluluk

$\mathrm{Bu}$ üç boyutu birbirinden bağımsız şekilde ele almak yerine bir bütün olarak incelemek gerekmektedir. Sürdürülebilirlik için en temel gereksinim ekonomik uygulanabilirliktir. Çünkü ekonomik olarak uygulanabilirliği mümkün olmayan bir girişimin varlığını sürdürmesi mümkün olmayacaktır. Ancak sürdürülebilirlik, esasında sosyal sorumluluğun bir gereği olup, toplumu ilgilendiren ve toplumun bir unsuru olan işletmeyi ve içindekileri de kapsayan bir özelliğe sahiptir. Çevresel sorumluluk ise toplum sağlığı başta olmak üzere sosyal sorumluluğun önemli bir parçasını oluşturmaktadır. 
Gün geçtikçe daha fazla şirketin dikkatini çeken sürdürülebilirliğin şirket faaliyetlerine sağladığı katkılar şu şekilde sıralanabilir (Borsa İstanbul, 2020: 38-43):

- Finansal Sermayeye Erişim Kolaylaşır: Sürdürülebilirlik ilkelerine uygun bir şekilde faaliyet gösterilmemesi, söz konusu işletmenin de sürekliliğine yönelik bir risk unsuru olarak görülmektedir. Bunun bir sonucu olarak, finans kuruluşları tarafından riskli şirketlere daha az finansman sağlama durumunun daha sik gündeme gelmesi beklenmektedir.

- Şirketin Marka Değeri ve İtibarı Güçlenir: Sürdürülebilir kalkınma amaçlarını faaliyetlerinde içselleştirerek, ortaya koyulan performansı kamuoyu ile paylaşan şirketlerin toplum tarafindan olumlu bir şekilde karşılanması, söz konusu şirketlerin itibarını ve marka değerini yükseltmektedir. Örneğin spor malzemeleri üretimi yapan bir firmanın tedarikçilerinin kötü çalışma koşullarına sahip olması nedeniyle hisse fiyatının düşmesi, şirketin marka değerinde ve itibarında yaşadığı güç kaybı olarak dikkat çekmektedir.

- Maliyet Tasarrufu Sağlanır ve Verimlilik Artar: Daha düşük enerji tüketimi, daha az hammadde kullanımı, geri dönüşüm ve yeniden kullanıma yönelme ile su gibi doğal kaynakların tasarrufu başta olmak üzere birçok iyileştirmeler, maliyetlerin aşağı çekilmesine, dolayısıyla verimlilikte ve kârlılıkta artışa yol açacaktır.

- Risk Yönetiminde Artış Sağlar: Şirketler hem piyasa koşullarına ve ihtiyaçlarına hızlı uyum sağlamalı hem de ekonomik, sosyal, çevresel ve kurumsal riskleri etkin bir şekilde yöneterek sermaye maliyetini azaltmalıdır. Eğer bir şirket iş modellerine sürdürülebilirliği entegre edebilmişse, söz konusu riskleri proaktif ve etkin bir şekilde yönetebilecektir.

- Yeni İş Fırsatları ve Yeni Pazarlara Erişim İmkânı Doğar: Tüketiciler başta olmak üzere farklı gruplardan geri bildirimlerin alınmasi; piyasaya yeni ürünlerin sunulmasına, alternatif süreçlerin geliştirilmesine ve yeni pazarların keşfedilmesine katkı sağlayacaktır. Sürdürülebilirlik bakış açısı inovasyonu tetikleyecek; beyaz eşya ve otomobil gibi ürünlerde enerji tasarrufu ön plana çıkacaktır.

- Nitelikli İşgücünü Çekmeyi ve Elde Tutmayı Kolaylaştırır: Nitelikli çalışanlar, kendi kişisel değerleriyle uyumlu bir şekilde faaliyet gösteren şirketlerde çalışmayı tercih etmektedirler. Sürdürülebilirlik uygulamalarını benimseyen şirketler bu noktada nitelikli çalışanların tercih sebebi olmakta ve şirkete bağlılıklarını artırmaktadır.

- İş Süreçlerine Sürdürülebilirliğin Dahil Edilmesi, Şirket Varlığını da Sürdürülebilir Kılar: Sürdürülebilirliğin üretim süreçlerine entegre edilmesi yanında kurumsal yönetim ilkelerine uygun bir yönetim yapısının kurgulanması ve paydaşlarla sağlam bir iletişim kanalının kurulması gibi adımları hayata geçiren şirketlerde kurumsal yönetim kalitesinde artış, sermaye maliyetinde azalış ve daha geniş finansman olanaklarına ulaşma imkânı ortaya çıkacaktır.

Çevre duyarlılığı özellikle büyük ölçekli şirketlerin yaptığ 1 çalışmalar ve örnek davranışlarla daha dikkat çekici bir hal almaktadır. Dolayısıyla söz konusu şirketlerin ortaya koyduğu bu bilinç, daha küçük çaplı işletmelerin de benzer bir yol izlemesine kapı aralamaktadır. Bu kapsamda çalışmalar ortaya koyan kuruluşlara ilişkin örnekler ise aşağıda verilmiştir (Borsa İstanbul, 2020: 49):

- California Üniversitesi: Eğitim faaliyetlerinin yanında 70 milyar dolarlık emeklilik fonunu ve 13 milyar dolarlık bağışı yöneten bir kuruluştur. 2019 yılında fosil yakıtlarla ilgili yatırımlarını sonlandırdığını açıklamıştır.

- Avrupa Yatırım Bankası: 2021 y1lı sonundan itibaren fosil yakıtlara ve doğalgaza dayalı projeleri finanse etmeyi durduracağını açılklamıştır.

- Kommunal Landspensjonskasse (KLP): Norveç'in en büyük emeklilik fonudur. 2019'dan itibaren katran kumu şirketlerine yatırım yapmayı durduracağını açılamıştır.

- Credit Suisse Asset Management: Önemli bir yatırım şirketidir. 2019'da çevresel sosyal ve kurumsal yönetim ilkelerini yatırım süreçlerine entegre edeceğini duyurmuştur.

- BlackRock: Dünyanın en büyük fon yöneticisidir. Sürdürülebilirlik odaklı borsa yatırım fonlarının sayısını ikiye katlayacağını ve 2020 yılında sürdürülebilir varlık portföyünü 10 yıl içerisinde 10 katına çıarmayı hedeflediğini ve bu kapsamda öncelikle aktif gelirlerinin dörtte birini termal kömürden elde eden şirketleri portföyünden çıkaracağını duyurmuştur.

Sürdürülebilirlik raporlaması kapsamında GRI standartları; çeşitli ekonomik, çevresel ve sosyal etkiler hakkında şirketlerin raporlama yapmasını sağlayan bir yapıya sahiptir. Standartlara dayalı bir şekilde bunun yapılıyor olması, sürdürülebilir kalkınmaya katkı sağlamaları yönünde şirketleri teşvik edici olmaktadır (www.globalreporting.org). Bu çalışmada çevresel unsurlar inceleneceği için sadece çevre ile ilgili GRI maddelerine ait açıklamalar Tablo 1'de verilmiştir. 
Tablo 1. Çevre ile İlgili GRI Maddeleri ve Açıklamaları

\begin{tabular}{|c|c|c|}
\hline & GRI Kodu & Açıklama \\
\hline 1 & $301-1$ & Ağırlık veya hacim olarak kullanılan malzemeler \\
\hline 2 & $301-2$ & Kullanılan geri dönüștürülmüș girdi malzemeleri \\
\hline 3 & $301-3$ & Geri kazanılmış ürünler ve bunların ambalaj malzemeleri \\
\hline 4 & $302-1$ & Organizasyon içi enerji tüketimi \\
\hline 5 & $302-2$ & Organizasyon dışındaki enerji tüketimi \\
\hline 6 & $302-3$ & Enerji yoğunluğu \\
\hline 7 & $302-4$ & Enerji tüketiminin azaltılması \\
\hline 8 & $302-5$ & Ürün ve hizmetlerin enerji ihtiyaçlarında azalma \\
\hline 9 & $303-1$ & Paylaşı1an bir kaynak olarak suyla etkileşimler \\
\hline 10 & $303-2$ & Su deşarjı ile ilgili etkilerin yönetimi \\
\hline 11 & $303-3$ & Su çekilmesi \\
\hline 12 & $303-4$ & Su tahliyesi \\
\hline 13 & $303-5$ & Su tüketimi \\
\hline 14 & $304-1$ & $\begin{array}{l}\text { Korunan alanların ve korunan alanların dışındaki yüksek biyoçeşitlilik değerine sahip } \\
\text { alanların sahip olduğu, kiraladığı, yönetildiği veya bunlara bitişik olan işletme sahaları }\end{array}$ \\
\hline 15 & $304-2$ & Faaliyetlerin, ürünlerin ve hizmetlerin biyoçeșitlilik üzerindeki önemli etkileri \\
\hline 16 & $304-3$ & Korunan veya restore edilen habitatlar \\
\hline 17 & $304-4$ & $\begin{array}{l}\text { Uluslararası doğayı koruma birliği kırmızı liste türleri ve operasyonlardan etkilenen } \\
\text { alanlarda yaşam alanlarına sahip ulusal koruma listesi türleri }\end{array}$ \\
\hline 18 & $305-1$ & Doğrudan (Kapsam 1) sera gazı emisyonları \\
\hline 19 & $305-2$ & Dolaylı enerji (Kapsam 2) sera gazı emisyonları \\
\hline 20 & $305-3$ & Diğer dolaylı (Kapsam 3) sera gazı emisyonları \\
\hline 21 & $305-4$ & Sera gazı emisyon yoğunluğu \\
\hline 22 & $305-5$ & Sera gazı emisyonlarının azaltılması \\
\hline 23 & $305-6$ & Ozon tabakasını incelten maddelerin (ODS) emisyonları \\
\hline 24 & $305-7$ & Azot oksitler (NOX), sülfür oksitler (SOX) ve diğer önemli hava emisyonları \\
\hline 25 & $306-1$ & Atık oluşumu ve atıkla ilgili önemli etkiler \\
\hline 26 & $306-2$ & Atıkla ilgili önemli etkilerin yönetimi \\
\hline 27 & $306-3$ & Üretilen atık \\
\hline 28 & $306-4$ & Bertaraftan yönlendirilen atık \\
\hline 29 & $306-5$ & Bertarafa yönlendirilen atık \\
\hline 30 & $307-1$ & Çevre yasa ve yönetmeliklerine uyulmaması \\
\hline 31 & $308-1$ & Çevresel kriterler kullanılarak taranan yeni tedarikçiler \\
\hline 32 & $308-2$ & Tedarik zincirindeki olumsuz çevresel etkiler ve alınan önlemler \\
\hline
\end{tabular}

Kaynak:www.globalreporting.org/how-to-use-the-gri-standards/gri-standards-english-language.

Yukarıda 32 maddeden oluşan standartlar sırasıyla malzeme (301), enerji (302), su ve atık su (303), biyoçeşitlilik (304), emisyon (305), atık (306), çevreye uyum (307) ve tedarikçinin çevresel değerlendirmesi (308) olmak üzere 8 kategoriden oluşmaktadır (www.globalreporting.org).

\section{LITERATÜR İNCELEMESI}

Çankaya ve Sezen (2015) tarafından yapılan çalışmada 281 imalat işletmesine anket uygulanarak ekolojik yenilik uygulamalarının sürdürülebilirlik performansı üzerindeki etkisinin incelenmesi ve bunlar arasındaki ilişkide çevresel belirsizliğin düzenleyici rolünün ortaya koyulması amaçlanmıştır. Çalışma sonucunda ekolojik ürün yeniliği ve ekolojik süreç yeniliği ile sürdürülebilirlik boyutları olan çevre performansı, ekonomik performans ve sosyal performans arasında pozitif yönlü ilişki olduğu belirlenmiştir. Bunun yanında sadece ekolojik süreç yeniliği ve sürdürülebilirlik boyutları arasında çevresel belirsizliğin düzenleyici rolünün bulunduğu ortaya koyulmuştur.

Özerhan ve Sultanoğlu (2018) tarafından yapılan çalışmada 2015 y1lı için Borsa İstanbul'da sürdürülebilirlik endeksinde yer alan 42 işletmeye ait sürdürülebilirlik raporları ve faaliyet raporları incelenmiştir. Çalışmanın amacı söz konusu raporlarda çevresel bilgilerin türü ve düzeyini incelemek, ayrıca güvence denetiminin yürütülme durumunu belirlemektir. Çalışma sonucunda çevresel bilgiyi raporlama konusunda işletmelerin standardizasyon eksikliğinin bulunduğu ve bu nedenle paydaşlara tutarlı ve karşılaştırılabilir bilgi aktarımı sağlanamadığı görülmüştür. Ayrıca söz konusu endekste yer alan sadece iki şirketin güvence denetimi yaptırdığ tespit edilmiştir. 
Şendurur ve Temelli (2018) tarafından yapılan çalışmada Türkiye'de faaliyet gösteren geleneksel bankalar ile katılım bankalarının faaliyet raporlarında sosyal ve çevresel alanlarda yaptıkları açıklamalar incelenerek sürdürülebilirlik puanları belirlenmiş ve çoklu regresyon analizi yapılarak sürdürülebilirlik raporları ile belirlenen değişkenler arasındaki ilişki incelenmiştir. Ayrıca belirlenen değişkenlerin grupları ve bankaların türlerine göre belirlenen grupları arasında anlamlı bir fark olup olmadığı araştırılmıştır. Çalışma sonucunda elde edilen bulgulara göre sahiplik yapısı ve ülke menşei ile sürdürülebilirlik raporları arasında anlamlı bir ilişki bulunamamıştır. Bunun yanında büyüklük, likidite, kârlılık, yaş, çevre puanı ve sürdürülebilirlik puanları ile banka türleri arasında anlamlı bir ilişkinin olduğu belirlenmiştir.

Arıc1 (2018), sürdürülebilirlik raporlamasının entegre raporlama sürecindeki etkisi üzerine gerçekleştirdiği çalışmada sürdürülebilirlik raporlaması ve entegre raporlama için toplanan verileri sistematik bir şekilde sunduktan sonra Türkiye ile OECD'ye üye ülkeler arasında karşılaştırma yapmıştır. Çalışma sonucunda OECD ülkeleri arasında Türkiye'nin sürdürülebilirlik raporlamasında oldukça geri sıralarda yer almasına karşılık entegre raporlamaya daha fazla uyum sağladığ 1 belirlenmiştir.

Gümrah ve Büyükipekçi (2019) tarafından yapılan çalışma, 2008-2017 yılları arasında Türkiye'deki sürdürülebilirlik raporlarının mevcut durumunu ortaya koymak ve rapor yayınlayan işletmelerin büyüklükleri ile raporda yer verdikleri gösterge sayıları arasında ilişki olup olmadığını belirlemek amacıyla yapılmıştır. İçerik analizi yönteminin kullanıldığ 1 çalışmada en fazla sayıda raporun holdingler tarafından, en az sayıda raporun ise kâr amacı gütmeyen ve elektronik sektöründe faaliyet gösteren kuruluşlar tarafından yayınlandığ1 belirlenmiştir. Ayrıca raporda yer verilen gösterge sayıları açısından küçük ve orta büyüklükteki işletmeler ile büyük ve çok uluslu işletmeler arasında istatistiksel olarak anlamlı bir farklılığın olduğu belirlenmiştir.

Çokmutlu ve Ok (2019) tarafından yapılan çalışmada, Borsa İstanbul'da sürdürülebilirlik endeksinde yer alan işletmelerin sundukları finansal olmayan raporlarda ISAE 3410 "Sera Gazı Beyanlarına İlişkin Güvence Denetim Standardı"na ilişkin açıklamaları incelenmiştir. Söz konusu raporlardan içerik analizi yöntemiyle elde edilen veriler frekans dağılımı ile çözümlenmiştir. Çalışma sonucunda işletmelerin sera gazına ilişkin beyanlarının yüksek düzeyde olduğu ve ISAE 3410 standardına ilişkin farkındalıklarının bulunduğu anlaşılmıştır.

Süklüm ve Hiçyorulmaz (2019) tarafından yapılan çalışmada BİST sürdürülebilirlik endeksinde yer alan 63 işletmenin sürdürülebilirlik, sosyal sorumluluk ve çevre faaliyetleri yanında çevre maliyetlerine finansal tablolarında yer verme durumları incelenmiştir. Söz konusu işletmelerin çevre muhasebesini uygulamadıkları ortaya koyulmuştur.

Karadeniz ve Uzpak (2019) tarafindan yapılan çalışmada 2017 yılında dünyadaki en yüksek marka değerine sahip otel zincirlerinden ilk beşinin faaliyetleri sürdürülebilirlik açısından incelenmiştir. Bu kapsamda faaliyet raporları ve sürdürülebilirlik raporları içerik analizine tabi tutulmuştur. Çalışma sonucunda söz konusu işletmelerin genel olarak ekonomik ve sosyal unsurlara karşılık çevresel unsurlara raporlarında yeterince yer vermedikleri belirlenmiştir.

A ğ ve Güler Sülük (2019) tarafından yapılan çalışmada Erzurum ili organize sanayi bölgesindeki üretim işletmelerine anket uygulanarak elde edilen veriler üzerinden söz konusu işletmelerin sürdürülebilirlik, çevre, çevresel riskler ve çevre muhasebesi konularındaki yaklaşımları tespit edilmeye çalışılmıştır. Çoklu regresyon ve korelasyon analizi sonucunda elde edilen bulgulara göre sürdürülebilirlik, çevre riskleri, çevre muhasebesi ve çevre politikalarına ilişkin hipotezler için anlamlı ve pozitif etkiye sahip olduğu belirlenmiştir. Ayrıca şirketlerin \%89,2'sinin çevre sorunlarının önlenmesinde çevreye zarar vermeyen kaynakların kullanılmasını önemsedikleri tespit edilmiştir.

Yılmaz ve Bayrak Oğuz (2020) tarafından yapılan çalışmada Türkiye'deki konaklama işletmelerinin sürdürülebilirlik raporları incelenmiştir. İçerik analizi yöntemi kullanılarak elde edilen veriler GRI raporlama standartları ve GRI turizm göstergelerinin karşılaştırılmasında kullanılmıştır. Çalışma sonucunda ulaşılan bulgulara göre konaklama işletmelerinin sürdürülebilirlik raporlarında en fazla sosyal boyuta yer verdikleri, ekonomik boyutun ise söz konusu raporlarda en az yer verilen unsur olduğu görülmüştür. Ayrıca sürdürülebilirlik raporlarında GRI standartlarına uygun raporlama yapılmadığ 1 belirlenmiştir.

Yeşilçelebi (2020) tarafından yapılan çalışmada bağımsız denetim kuruluşlarının yayınladıkları sürdürülebilirlik raporlarında sürdürülebilirlik boyutlarına ne ölçüde yer verdikleri içerik analizi yöntemiyle belirlenmeye çalışılmıştır. 334 bağımsız denetim kuruluşundan sadece ikisinin toplam beş yıl sürdürülebilirlik raporu yayınladığı ve bu raporlarda yer alan bilgilerin doğruluğu konusunda güvence verilmediği belirlenmiştir.

Karadeniz ve Uzpak (2020) tarafindan yapılan çalışma, Borsa İstanbul'da işlem gören konaklama şirketlerinin faaliyet raporlarında sürdürülebilirlik konularını ne ölçüde ele aldığını ortaya koymayı amaçlamaktadır. 2017, 2018 ve 2019 yıllarını kapsayan çalışmada içerik analizi uygulanmış olup genel olarak 
konaklama işletmelerinin sürdürülebilirlik faaliyetlerine ilişkin raporlama düzeylerinin yetersiz olduğu sonucuna varılmıştır.

Sak ve Dalgar (2020) tarafindan yapılan çalışmada işletmelerin kurumsal sürdürülebilirlik çalışmalarının finansal performans üzerinde bir etkisi olup olmadığının belirlenmesi amaçlanmıştır. BİST Kurumsal Sürdürülebilirlik Endeksinde yer alan banka dışı 35 işletmenin 2013-2016 yılları arasındaki döneme ait 16 çeyrek dönemlik finansal bilgileri kullanılarak panel veri analizi uygulanmıştır. Çalışma sonucunda kurumsal sürdürülebilirlik uygulamalarının finansal performans üzerinde anlamlı ve pozitif yönlü etkisinin olduğu belirlenmiştir.

Emir ve Kıymık (2021) tarafından yapılan çalışmada BİST Metal Eşya, Makine Endeksindeki şirketlerin GRI ilkelerine göre sürdürülebilirlik düzeyleri belirlenmiştir. 2014-2018 yıllarını kapsayan bu çalışmada sürdürülebilirlik düzeylerinin finansal performansa etkisini ölçmek için panel veri regresyon analizi uygulanmıştır. Elde edilen sonuçlara göre "sürdürülebilirlik performans göstergelerine ilişkin açıklanan bilgi düzeyiyle, şirketlerin aktif kârlılığı, özkaynak kârlılı̆̆ 1 , kullanılan sermaye getirisi ve vergi öncesi kâr arasında istatistiki olarak anlamlı pozitif yönlü bir ilişki olduğu; toplam varlıklarda büyüme oranıyla ise istatistiki olarak negatif yönlü anlamlı bir ilişki olduğu" belirlenmiştir.

Sürdürülebilirlik raporlamasına ilişkin çalışmaların genel olarak içerik analizi şeklinde yapıldığı, entegre raporlama süreciyle ilişkilendirildiği ve işletme karlılığ 1 veya hisse senedi getirisine etkisi üzerine yapıldığ görülmektedir.

\section{METODOLOJI}

\subsection{Araştırmanın Amacı ve Önemi}

Araştırmanın amacı, Borsa İstanbul'a kayıtlı olup internet sayfalarında sürdürülebilirlik raporu yayınlayan şirketlerin söz konusu raporlarda GRI maddelerine ne ölçüde yer verdiklerini; ayrıca GRI maddeleri ve GRI kategorilerine ait sayılar ile sektörler arasında anlamlı bir ilişki olup olmadığını belirlemektir.

GRI maddelerinin sayısı ve GRI kategorilerinin sayısı ile sektörler arasındaki ilişkiyi inceleyen herhangi bir çalışmaya ulaşılamamış olması bu çalışmanın önemini oluşturmaktadır.

\subsection{Araştırmanın Kapsamı ve Sınırlııkları}

Araştırma BİST 100 endeksine kayıtlı olup 2019 y1lına ait sürdürülebilirlik raporunu yayınlayan ve raporunda GRI içerik indeksine yer veren şirketlerin çevre ile ilgili olan unsurlarını kapsamaktadır. Dolayısıyla 2019 yılına ait verilerin kullanılması, raporlarda GRI içerik indeksi bulunmayanların kapsam dışında tutulması, çevre ile ilgili olan unsurların incelenmesi ve sadece BİST 100 endeksinde yer alan şirketlerin incelemeye dahil edilmesi çalışmanın kısıtlarını oluşturmaktadır.

\subsection{Araştırmanın Yöntemi}

Araştırma kapsamında öncelikle internet sayfalarında sürdürülebilirlik raporu yayınlayan BİST 100 endeksindeki şirketlerin söz konusu raporlarına ulaşılmıştır. Bu raporlar içerisinden GRI içerik indeksine yer vermeyen raporlar kapsam dışında bırakılmıştır. Elde edilen raporlardan hangi şirketin hangi GRI maddesine yer verdiği belirlenmiş ve tablolar halinde ortaya koyulmuştur. Şirketlerin raporladığı GRI madde sayıları belirlenerek raporda kaç maddeye yer verdikleri belirlenmiştir. Sonrasında 8 kategoriden oluşan GRI maddelerine şirketlerin ne ölçüde yer verdikleri belirlenmiştir. Raporlanan GRI madde sayısının sektörlere göre farklılık gösterme durumunu incelemek amacıyla ANOVA uygulanmıştır. Son olarak raporlanan GRI kategori sayısının sektörlere göre farklılık gösterme durumunu belirlemek amacıyla Kruskal Wallis H testi uygulanmıştır.

\section{ARAŞTIRMANIN BULGULARI}

BİST 100 endeksinde toplam 46 şirketin internet sayfasında sürdürülebilirlik raporuna ulaşılmıştır. Söz konusu raporlar incelenerek şirketlerin GRI içerik indekslerinde çevre ile ilgili hangi maddelere yer verdikleri aşağıdaki tablolarda belirtilmiştir. 
Tablo 2. Şirketlerin Sürdürülebilirlik Raporunda Yer Alan GRI Maddeleri (1)

\begin{tabular}{|c|c|c|c|c|c|c|c|c|c|c|c|c|c|c|c|c|}
\hline & 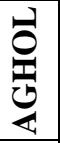 & $\frac{u}{2}$ & $\underset{\mho}{\mathscr{Z}}$ & 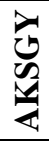 & 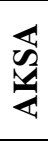 & $\frac{Z}{2}$ & $\frac{1}{2}$ & 㝳 & $\begin{array}{l}\infty \\
\frac{1}{x} \\
\frac{1}{4}\end{array}$ & 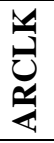 & 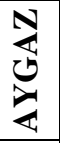 & $\underset{\Delta}{\mathbf{N}}$ & $\underset{\circlearrowright}{\circlearrowright}$ & $\sum^{\mathscr{\omega}}$ & $\underbrace{\infty}_{0}$ & 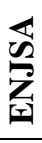 \\
\hline 301-1 & & & $*$ & & & & & $*$ & & $*$ & & & & & & \\
\hline 301-2 & & & $*$ & & & & & & & & & & $*$ & $*$ & & \\
\hline 301-3 & & & & & & & & $*$ & & $*$ & & & $*$ & $*$ & & \\
\hline 302-1 & & $*$ & $*$ & $*$ & $*$ & $*$ & $*$ & $*$ & $*$ & $*$ & $*$ & $*$ & $*$ & $*$ & $*$ & $*$ \\
\hline 302-2 & & $*$ & & & $*$ & & & $*$ & & $*$ & & & $*$ & & $*$ & \\
\hline 302-3 & $*$ & $*$ & $*$ & $*$ & $*$ & $*$ & & $*$ & $*$ & & & & $*$ & & $*$ & $*$ \\
\hline $302-4$ & $*$ & $*$ & $*$ & $*$ & $*$ & $*$ & & $*$ & $*$ & $*$ & $*$ & & $*$ & $*$ & $*$ & \\
\hline $302-5$ & & & & & & & $*$ & $*$ & $*$ & $*$ & & & $*$ & & $*$ & \\
\hline 303-1 & $*$ & $*$ & $*$ & $*$ & $*$ & $*$ & $*$ & $*$ & $*$ & $*$ & $*$ & & $*$ & $*$ & $*$ & $*$ \\
\hline 303-2 & & $*$ & $*$ & & $*$ & & & & $*$ & & & & $*$ & & & \\
\hline 303-3 & $*$ & $*$ & & & $*$ & $*$ & $*$ & $*$ & $*$ & $*$ & $*$ & & $*$ & $*$ & & \\
\hline 303-4 & & & & & & & & & $*$ & & & & & & & \\
\hline 303-5 & & & $*$ & & & & & & & & & & & & & \\
\hline 304-1 & & & $*$ & & $*$ & & & & & & & & & $*$ & & \\
\hline 304-2 & & & $*$ & & $*$ & & & & & & & & & & & \\
\hline 304-3 & $*$ & & $*$ & & & $*$ & & & & & & & & $*$ & & \\
\hline 304-4 & & & & & & $*$ & & & & & & & & $*$ & & \\
\hline 305-1 & $*$ & $*$ & $*$ & & $*$ & $*$ & $*$ & $*$ & $*$ & $*$ & $*$ & & $*$ & $*$ & $*$ & $*$ \\
\hline 305-2 & $*$ & $*$ & $*$ & & $*$ & $*$ & & $*$ & $*$ & $*$ & $*$ & & $*$ & & $*$ & $*$ \\
\hline 305-3 & $*$ & $*$ & & & $*$ & & & $*$ & $*$ & & $*$ & & $*$ & & $*$ & \\
\hline $305-4$ & $*$ & $*$ & $*$ & & $*$ & $*$ & & $*$ & $*$ & & & & $*$ & $*$ & . & $*$ \\
\hline 305-5 & & $*$ & $*$ & & $*$ & $*$ & & $*$ & $*$ & $*$ & $*$ & $*$ & $*$ & $*$ & $*$ & \\
\hline 305-6 & & $*$ & $*$ & & & & & & & & & & & & & \\
\hline 305-7 & $*$ & $*$ & $*$ & & $*$ & $*$ & & $*$ & & & & & & $*$ & & $*$ \\
\hline 306-1 & $*$ & $*$ & $*$ & & $*$ & & & & & $*$ & & & $*$ & $*$ & $*$ & $*$ \\
\hline 306-2 & $*$ & $*$ & $*$ & $*$ & $*$ & $*$ & & $*$ & $*$ & $*$ & $*$ & & $*$ & $*$ & $*$ & $*$ \\
\hline 306-3 & & & $*$ & & & & & & & & & & & & & \\
\hline $306-4$ & & & $*$ & & & & & & & & & & & & $*$ & \\
\hline $306-5$ & & & $*$ & & & & & & & & & & & $*$ & & \\
\hline 307-1 & & & $*$ & & & $*$ & $*$ & & & & $*$ & & $*$ & & & $*$ \\
\hline 308-1 & & & & & & & & $*$ & & $*$ & & & $*$ & & $*$ & \\
\hline 308-2 & & & & & & & & $*$ & & $*$ & & & & & $*$ & \\
\hline
\end{tabular}

*: sürdürülebilirlik raporunda yer verilen madde.

Tablo 3. Şirketlerin Sürdürülebilirlik Raporunda Yer Alan GRI Maddeleri (2)

\begin{tabular}{|c|c|c|c|c|c|c|c|c|c|c|c|c|c|c|c|}
\hline & $\underset{z}{Z}$ & 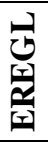 & $\begin{array}{l}0 \\
0 \\
0 \\
\frac{1}{x}\end{array}$ & $\underset{\widetilde{\sigma}}{\stackrel{2}{2}}$ & 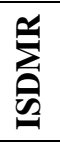 & 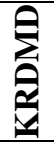 & $\frac{1}{\alpha}$ & $\underset{\theta}{0}$ & $\begin{array}{l}\mathscr{2} \\
\stackrel{2}{a} \\
\stackrel{a}{0}\end{array}$ & 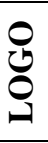 & 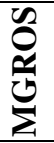 & 感 & 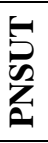 & 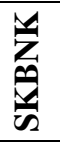 & $\frac{\sum}{0}$ \\
\hline 301-1 & & & & & & $*$ & & & $*$ & & & & & & \\
\hline 301-2 & & * & & & $*$ & & & & $*$ & & & & & & \\
\hline \multicolumn{16}{|l|}{ 301-3 } \\
\hline 302-1 & $*$ & & $*$ & * & & * & $*$ & * & * & * & $*$ & $*$ & $*$ & * & $*$ \\
\hline 302-2 & & & & & & & & & & & & & & * & \\
\hline $302-3$ & $*$ & & $*$ & $*$ & & $*$ & $*$ & $*$ & & $*$ & & $*$ & $*$ & $*$ & \\
\hline $302-4$ & $*$ & * & $*$ & $*$ & $*$ & $*$ & $*$ & $*$ & & $*$ & $*$ & $*$ & $*$ & $*$ & $*$ \\
\hline 302-5 & & & & & & & & & $*$ & & & $*$ & * & * & \\
\hline 303-1 & $*$ & $*$ & $*$ & * & $*$ & & $*$ & * & $*$ & $*$ & $*$ & * & * & * & \\
\hline 303-2 & $*$ & & & & & & & & & & & $*$ & $*$ & $*$ & \\
\hline 303-3 & * & * & $*$ & $*$ & $*$ & * & $*$ & $*$ & $*$ & $*$ & & $*$ & * & * & $*$ \\
\hline 303-4 & * & & & & & * & & & & & & & $*$ & & \\
\hline
\end{tabular}




\begin{tabular}{|l|l|l|l|l|l|l|l|l|l|l|l|l|l|l|l|}
$\mathbf{3 0 3 - 5}$ & $*$ & & & & & & & & & & & & & & \\
\hline $\mathbf{3 0 4 - 1}$ & $*$ & & & & & & & & & & $*$ & & & & \\
\hline $\mathbf{3 0 4 - 2}$ & & & & & & & & & & & $*$ & & & & \\
\hline $\mathbf{3 0 4 - 3}$ & & & & $*$ & & & & & & & & & & & \\
\hline $\mathbf{3 0 4 - 4}$ & & & & & & & & & & & & & & & \\
\hline $\mathbf{3 0 5 - 1}$ & $*$ & & $*$ & $*$ & & & $*$ & $*$ & $*$ & $*$ & $*$ & $*$ & $*$ & $*$ & $*$ \\
\hline $\mathbf{3 0 5 - 2}$ & $*$ & & $*$ & $*$ & & & $*$ & $*$ & $*$ & $*$ & $*$ & $*$ & $*$ & $*$ & $*$ \\
\hline $\mathbf{3 0 5 - 3}$ & $*$ & & & $*$ & & & & & & $*$ & $*$ & & & $*$ & \\
\hline $\mathbf{3 0 5 - 4}$ & $*$ & & $*$ & $*$ & & & $*$ & $*$ & & $*$ & $*$ & $*$ & $*$ & $*$ & \\
\hline $\mathbf{3 0 5 - 5}$ & $*$ & $*$ & $*$ & $*$ & $*$ & $*$ & $*$ & $*$ & & $*$ & $*$ & $*$ & $*$ & $*$ & \\
\hline $\mathbf{3 0 5 - 6}$ & & & & & & & & & & & & & & & \\
\hline $\mathbf{3 0 5 - 7}$ & $*$ & & & & & & & & & & & & & & \\
\hline $\mathbf{3 0 6 - 1}$ & & & $*$ & & & & & & & & $*$ & $*$ & & & \\
\hline $\mathbf{3 0 6 - 2}$ & $*$ & $*$ & $*$ & $*$ & $*$ & & $*$ & $*$ & $*$ & $*$ & $*$ & $*$ & & & $*$ \\
\hline $\mathbf{3 0 6 - 3}$ & $*$ & & & & & $*$ & & & & & & & & & \\
\hline $\mathbf{3 0 6 - 4}$ & & & & & & & & & & & & & & & \\
\hline $\mathbf{3 0 6 - 5}$ & & & & & & & & & & & & & & & \\
\hline $\mathbf{3 0 7 - 1}$ & $*$ & & $*$ & & & & & & & & $*$ & $*$ & $*$ & & \\
\hline $\mathbf{3 0 8}-1$ & $*$ & & $*$ & & & & $*$ & & $*$ & & $*$ & & $*$ & & $*$ \\
\hline $\mathbf{3 0 8 - 2}$ & $*$ & & & & & & & $*$ & & & $*$ & & $*$ & & \\
\hline
\end{tabular}

*: sürdürülebilirlik raporunda yer verilen madde.

Tablo 4. Şirketlerin Sürdürülebilirlik Raporunda Yer Alan GRI Maddeleri (3)

\begin{tabular}{|c|c|c|c|c|c|c|c|c|c|c|c|c|c|c|c|}
\hline & Z & $\frac{0}{\mathscr{0}}$ & $\underset{\theta}{\sigma}$ & है & 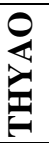 & $\underset{b}{Z}$ & $\stackrel{\theta}{*}$ & 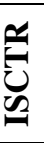 & $\stackrel{\theta}{\mathscr{L}}$ & $\frac{\sqrt{n}}{\sqrt[D]{2}}$ & $\underset{8}{Z}$ & $\frac{\mathscr{a}}{\sqrt{2}}$ & 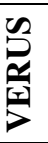 & $\underset{\nu}{n}$ & 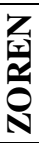 \\
\hline 301-1 & & & & $*$ & & & & & & & & $*$ & & & \\
\hline \multicolumn{16}{|l|}{ 301-2 } \\
\hline \multicolumn{16}{|l|}{ 301-3 } \\
\hline 302-1 & $*$ & $*$ & $*$ & $*$ & $*$ & $*$ & $*$ & $*$ & $*$ & $*$ & $*$ & $*$ & $*$ & $*$ & $*$ \\
\hline 302-2 & & & & & $*$ & $*$ & $*$ & $*$ & $*$ & & & & & & \\
\hline 302-3 & & $*$ & & $*$ & * & & $*$ & $*$ & $*$ & & & $*$ & & $*$ & $*$ \\
\hline 302-4 & $*$ & $*$ & $*$ & $*$ & & $*$ & $*$ & $*$ & $*$ & & $*$ & $*$ & $*$ & & $*$ \\
\hline $302-5$ & & & & & & & $*$ & $*$ & & & & & & & $*$ \\
\hline 303-1 & $*$ & & $*$ & & $*$ & $*$ & $*$ & $*$ & $*$ & $*$ & $*$ & $*$ & $*$ & & $*$ \\
\hline 303-2 & $*$ & & & & & $*$ & & & & & & & & & $*$ \\
\hline 303-3 & $*$ & & $*$ & $*$ & & $*$ & & $*$ & $*$ & $*$ & & $*$ & $*$ & $*$ & $*$ \\
\hline 303-4 & $*$ & & & $*$ & & & & & & & & & & & $*$ \\
\hline 303-5 & $*$ & & $*$ & & & & & & & & & & & & $*$ \\
\hline 304-1 & & & & & & & & & & & & & & & $*$ \\
\hline 304-2 & & & & & & & & $*$ & & & & & & & $*$ \\
\hline 304-3 & & & & & & & & & & & & & & & $*$ \\
\hline 304-4 & & & & & & & & & & & & & & & $*$ \\
\hline 305-1 & $*$ & $*$ & $*$ & & $*$ & $*$ & $*$ & $*$ & $*$ & $*$ & $*$ & $*$ & $*$ & $*$ & $*$ \\
\hline 305-2 & $*$ & $*$ & $*$ & & $*$ & $*$ & $*$ & $*$ & $*$ & $*$ & $*$ & $*$ & $*$ & $*$ & $*$ \\
\hline 305-3 & $*$ & & $*$ & & & $*$ & & $*$ & $*$ & & $*$ & $*$ & $*$ & $*$ & $*$ \\
\hline $305-4$ & $*$ & $*$ & $*$ & & & $*$ & $*$ & $*$ & $*$ & & $*$ & $*$ & & $*$ & $*$ \\
\hline $305-5$ & $*$ & $*$ & & $*$ & $*$ & $*$ & $*$ & $*$ & $*$ & $*$ & $*$ & $*$ & $*$ & $*$ & $*$ \\
\hline 305-6 & & & $*$ & & & & & & & & & & & & $*$ \\
\hline 305-7 & & $*$ & & & $*$ & & & & & & & $*$ & & & $*$ \\
\hline 306-1 & & $*$ & & & & & $*$ & $*$ & & $*$ & & & & & \\
\hline 306-2 & $*$ & $*$ & $*$ & & $*$ & $*$ & $*$ & $*$ & $*$ & $*$ & & $*$ & $*$ & $*$ & \\
\hline 306-3 & & & & $*$ & & & & & & & & & & & \\
\hline \multicolumn{16}{|l|}{$306-4$} \\
\hline 306-5 & & $*$ & & & & & & & & & & & & & \\
\hline 307-1 & & & $*$ & $*$ & $*$ & & & & & & $*$ & $*$ & $*$ & & $*$ \\
\hline
\end{tabular}




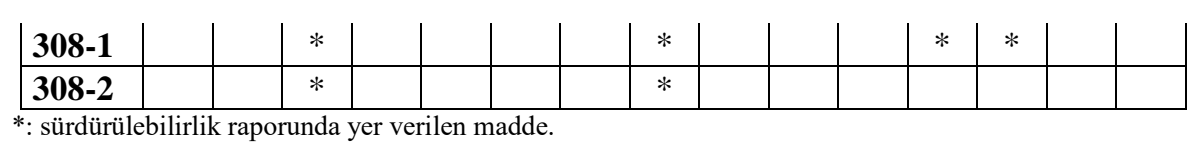

Analiz kapsamındaki 46 şirket, BİST'te yer aldıkları sektörlere göre sınıflandırılmış ve aşağıdaki tabloda bunlara ait frekans değerlerine yer verilmiştir.

Tablo 5. Şirketlerin Bulundukları Sektörlere Göre Dağılımı

\begin{tabular}{|l|c|c|}
\hline \multicolumn{1}{|c|}{ Sektörler } & Şirket Sayısı & Yüzde \\
\hline İmalat & 18 & 39 \\
\hline Mali Kuruluşlar & 16 & 35 \\
\hline Toptan ve Perakende Ticaret, Lokantalar ve Oteller & 4 & 9 \\
\hline Elektrik, Gaz ve Su & 3 & 7 \\
\hline Teknoloji & 2 & 4 \\
\hline Ulaştırma, Depolama ve Haberleşme & 2 & 4 \\
\hline İnşaat ve Bayındırlık & 1 & 2 \\
\hline Toplam & $\mathbf{4 6}$ & $\mathbf{1 0 0}$ \\
\hline
\end{tabular}

Tablo 5'e göre toplam 46 şirketin 18'i imalat (\%39), 16's1 mali kuruluşlar (\%35), 4'ü toptan ve perakende ticaret, lokantalar ve oteller (\%9), 3'ü elektrik, gaz ve su (\%7), 2'si teknoloji (\%4), 2'si ulaştırma, depolama ve haberleşme (\%4) ve 1'i inşaat ve bayındırlık (\%2) sektöründe yer almaktadır. İmalat ve mali kuruluşlar dışındakilerin az sayıda olması nedeniyle çalışmanın devamında bunlar "diğer" ismi altında incelemeye tabi tutulmuştur.

Tablo 6 ise şirket sayılarına göre raporlanan GRI madde sayılarına ait dağılımı göstermektedir.

Tablo 6. Şirket Sayılarına Göre Raporlanan Toplam GRI Madde Sayıları

\begin{tabular}{|c|c|c|}
\hline $\begin{array}{c}\text { Raporlanan GRI } \\
\text { Madde Sayısı }\end{array}$ & Şirket Sayısı & Yüzde \\
\hline 2 & 1 & 2,2 \\
\hline 5 & 1 & 2,2 \\
\hline 6 & 3 & 6,5 \\
\hline 7 & 1 & 2,2 \\
\hline 8 & 2 & 4,3 \\
\hline 9 & 3 & 6,5 \\
\hline 10 & 4 & 8,7 \\
\hline 11 & 5 & 10,9 \\
\hline 12 & 5 & 10,9 \\
\hline 13 & 3 & 6,5 \\
\hline 14 & 4 & 8,7 \\
\hline 15 & 5 & 10,9 \\
\hline 16 & 2 & 4,3 \\
\hline 17 & 2 & 4,3 \\
\hline 18 & 1 & 2,2 \\
\hline 19 & 1 & 2,2 \\
\hline 20 & 1 & 2,2 \\
\hline 21 & 1 & 2,2 \\
\hline 23 & 1 & 2,2 \\
\hline Toplam & $\mathbf{4 6}$ & $\mathbf{1 0 0 , 0}$ \\
\hline
\end{tabular}

Tablo 6 incelendiğinde 23, 21, 20, 19 ve 18 maddenin birer şirket tarafından yayınlandığı, genel olarak bakıldığında ise en fazla \%10,9 oranla 11,12 ve 15 maddenin yayınlandığı; bunun yanında sadece 2 madde yayınlayan 1 şirketin bulunduğu görülmektedir.

Çevre ile ilgili GRI standartlarında 301, 302, 303, 304, 305, 306, 307 ve 308 olmak üzere toplam 8 kategori bulunmaktadır. Şirketlerin yayınladığı raporlarda söz konusu kategorilere ne ölçüde yer verildiğine ilişkin bilgi Tablo 7'de sunulmuştur. 
Tablo 7. Şirketlerin Raporlarında Yer Verdiği GRI Kategorilerinin Sayısı

\begin{tabular}{|c|c|c|}
\hline $\begin{array}{c}\text { Raporlanan } \\
\text { Kategori Sayısı }\end{array}$ & $\begin{array}{c}\text { Şirket } \\
\text { Sayısı }\end{array}$ & Yüzde \\
\hline 2 & 1 & 2,2 \\
\hline 3 & 3 & 6,5 \\
\hline 4 & 12 & 26,1 \\
\hline 5 & 15 & 32,6 \\
\hline 6 & 9 & 19,6 \\
\hline 7 & 6 & 13,0 \\
\hline Toplam & $\mathbf{4 6}$ & $\mathbf{1 0 0 , 0}$ \\
\hline
\end{tabular}

Tablo 7 incelendiğinde 6 şirket (\%13) tarafından 7 kategoriye, 9 şirket $(\% 19,6)$ tarafından 6 kategoriye, en fazla sayıda şirket tarafından (15 şirket - \%32,6) 5 kategoriye, 12 şirket $(\% 26,1)$ tarafindan 4 kategoriye, 3 şirket $(\% 6,5)$ tarafından 3 kategoriye ve 1 şirket $(\% 2,2)$ tarafından 2 kategoriye yer verildiği görülmektedir.

\subsection{Sektörlere Göre GRI Madde Sayılarının İncelenmesi}

$\mathrm{Bu}$ aşamada, şirketlerin yer aldığı sektörler ile şirketlerin raporladığı GRI maddelerinin sayısı arasında istatistiksel olarak anlamlı bir farklılık olup olmadığının incelenmesi amaçlanmıştır. Bu kapsamda araştırılan hipotezler aşağıda verilmiştir.

$\mathrm{H}_{0}$ : Raporlanan GRI madde sayısı sektörlere göre birbirinden farklı değildir.

$\mathrm{H}_{1}$ : Raporlanan GRI madde sayısı sektörlere göre birbirinden farklıdır.

Normallik testi sonucunda değişkenlerin normal dağıldığ $(\mathrm{P}>0,05)$ ve varyansların homojen yapıya sahip olduğu $(\mathrm{P}>0,05)$ belirlenmiştir. Gerekli koşullar sağlandığı için One-Way ANOVA testi uygulanmış ve aşağıdaki sonuçlar elde edilmiştir.

Tablo 8. Raporlanan GRI Madde Sayısının Sektörlere Göre ANOVA Sonuçları

\begin{tabular}{|l|c|c|c|c|c|}
\hline Sektörler & N & Ortalama & Std. Sapma & F & P \\
\hline İmalat & 18 & 12,89 & 4,471 & & \multirow{2}{*}{0,937} \\
\cline { 1 - 4 } Mali Kuruluşlar & 16 & 11,13 & 3,181 & \multirow{2}{*}{0,400} \\
\cline { 1 - 4 } Diğer & 12 & 13,08 & 5,452 & & \\
\hline
\end{tabular}

ANOVA sonucunda $\mathrm{P}>0,05$ olduğu için $(0,400) \mathrm{H}_{0}$ hipotezi reddedilememiştir. Dolayısılyla raporlanan GRI maddesi sayısı açısından sektörler arasında istatistiksel olarak anlamlı bir fark bulunamamıştır.

\subsection{Sektörlere Göre GRI Kategori Saylarının İncelenmesi}

$\mathrm{Bu}$ aşamada şirketlerin yer aldığı sektörler ile şirketlerin raporladığı GRI kategorilerinin sayısı arasında istatistiksel olarak anlamlı bir farklılık olup olmadığının incelenmesi amaçlanmıştır. Bu kapsamda araştırılan hipotezler aşağıda verilmiştir.

$\mathrm{H}_{0}$ : Raporlanan GRI kategori sayıları sektörlere göre birbirinden farklı değildir.

$\mathrm{H}_{1}$ : Raporlanan GRI kategori sayıları sektörlere göre birbirinden farklıdır.

Normallik testi sonucunda değişkenlerin normal dağılım göstermemesi nedeniyle $(\mathrm{P}<0,05)$ Kruskal Wallis $\mathrm{H}$ testi uygulanmış ve aşağıdaki sonuçlar elde edilmiştir.

Tablo 9. Raporlanan GRI Kategori Sayısının Sektörlere Göre Kruskal Wallis H Testi Sonuçları

\begin{tabular}{|c|c|c|c|c|}
\hline Sektörler & $\mathbf{N}$ & Ortalama & Ki-kare & $\mathbf{P}$ \\
\hline İmalat & 18 & 29,08 & \multirow{3}{*}{12,072} & \multirow{3}{*}{0,002} \\
\hline Mali Kuruluşlar & 16 & 14,44 & & \\
\hline Diğger & 12 & 27,21 & & \\
\hline
\end{tabular}

Kruskal Wallis $\mathrm{H}$ testi sonucunda $\mathrm{P}<0,05$ olduğu için $(0,002) \mathrm{H}_{0}$ hipotezi reddedilmiştir. Dolayısıyla raporlanan GRI kategori sayısı açısından sektörler arasında istatistiksel olarak anlamlı bir fark bulunmaktadır. Söz konusu farklılığın hangi gruplar arasında olduğunu tespit etmek amaciyla Games-Howell yöntemine göre Post Hoc testi uygulanmış ve sonuçları Tablo 10'da sunulmuştur. 
Tablo 10. Gruplar Arasındaki Farklılığın Tespiti için Post Hoc Testi Sonuçları

\begin{tabular}{|l|l|c|c|}
\hline \multicolumn{1}{|c|}{ Sektörler } & \multicolumn{1}{|c|}{ Sektörler } & Std. Hata & \multicolumn{1}{c|}{ P } \\
\hline \multirow{2}{*}{ İmalat } & Mali Kuruluşlar & 0,3359 & $\mathbf{0 , 0 0 2}$ \\
\cline { 2 - 4 } & Diğer & 0,4695 & 0,856 \\
\hline \multirow{2}{*}{ Mali Kuruluşlar } & İmalat & 0,3359 & $\mathbf{0 , 0 0 2}$ \\
\cline { 2 - 4 } & Diğer & 0,4464 & 0,092 \\
\hline \multirow{2}{*}{ Diğer } & Mali Kuruluşlar & 0,4464 & 0,092 \\
\cline { 2 - 4 } & İmalat & 0,4695 & 0,856 \\
\hline
\end{tabular}

Post Hoc testi sonuçlarına göre Sig. (P) değeri $(0,002)$, 05 ’ten küçük olduğu için söz konusu farklılığın mali kuruluşlar ile imalat sektörleri arasında olduğu belirlenmiştir.

\section{SONUÇ}

Finansal olmayan bir rapor olarak karşımıza çıkan sürdürülebilirlik raporları, herhangi bir zorunluluk olmaksızın hazırlanmaktadır. Raporu düzenleyen işletmenin çevresel, sosyal ve ekonomik sorumluluklara verdiği önemi gözler önüne sermek için kullanılan bu raporlarda genel olarak GRI standartlarının dikkate alındığı görülmektedir. Sürdürülebilirlik raporlarından farklı bir yapıya sahip olan çevre muhasebesi ise finansal raporlamayı esas almaktadır. Ayrıca çevre muhasebesinde sosyal ve ekonomik konulara doğrudan yer verilmeyip çevre üzerinde odaklanılmaktadır.

BİST 100 endeksinde yer alan 46 şirketin incelendiği çalışmada en fazla 23 maddenin 1 şirket tarafından raporlandığı, ayrıca 7 kategorinin 6 şirket tarafindan raporlandığg belirlenmiştir. Sektörler ile raporlanan GRI madde sayısı arasında anlamlı bir fark bulunamazken sektörler ile raporlanan GRI kategori sayısı arasında anlamlı bir fark bulunduğu ortaya koyulmuştur. Post Hoc testi sonucunda ise söz konusu farklılığın imalat sektörü ile mali kuruluşlar sektörü arasında olduğu belirlenmiştir.

Çalışmada sadece 2019 yılı dikkate alınarak araştırma yapılmıştır. Dolayısıyla bundan sonraki çalışmalarda diğer yıllar da dikkate alınarak karşılaştırma yapılabilir ve yıllara göre herhangi bir farklılık olup olmadığı belirlenebilir.

Sürdürülebilirlik, bugün var olan kaynakların en uygun şekilde kullanılmasıyla geleceğe bir yatırımdır. Dolayısıyla tüm toplumu ilgilendiren bu kavramın sahiplenilmesi, geleceğin de sahiplenilmesi anlamına gelmektedir. 


\section{KAYNAKÇA}

A $\breve{g}$, A. ve Güler Sülük, R. (2019). Sürdürülebilirlik, Çevresel Riskler ve Çevre Muhasebesi Arasındaki İlişkinin Tespiti: Erzurum İlinde Bir Araştırma. İşletme Araştırmaları Dergisi, 11 (3), 1945-1960.

Arıc1, N.D. (2018). Entegre Raporlama Yolculuğunda Sürdürülebilirlik Raporlamasının Rolü: OECD ve Türkiye Karşılaştırması. Mali Çözüm Dergisi, Eylül-Ekim, (149), 61-83.

Borsa İstanbul, (2020). Gelecekte var olmak, şirketler için sürdürülebilirlik rehberi. https://www.borsaistanbul.com/files/surdurulebilirlik-rehberi.pdf, Erişim Tarihi: 10.11.2020.

Çankaya, S.Y. ve Sezen, B. (2015). Ekolojik Yenilik ile Sürdürülebilirlik Performansı Arasındaki İlişkide Çevresel Belirsizliğin Moderatör Etkisi. Uluslararası Yönetim İktisat ve İşletme Dergisi, 11 (24), 111-134.

Çokmutlu, M.E. ve Ok, Ş. (2019). Borsa İstanbul Sürdürülebilirlik Endeksi İşletmelerinin Sera Gazı Beyanlarına Yönelik Güvence Denetimleri: ISAE 3410 Güvence Denetim Standardına İlişkin Bir Araştırma. IBAD Sosyal Bilimler Dergisi, (5), 164-174.

Emir, S. ve Kıymı, H. (2021). Sürdürülebilirlik Düzeyinin Finansal Performans Üzerindeki Etkisinin Değerlendirilmesi: Borsa İstanbul'da Bir Araştırma. Muhasebe ve Vergi Uygulamaları Dergisi, 14 (1), 101-128.

Gould, S. (2011). Accounting for Sustainability. Finance \& Management, Accountancy Plus, Issue 01, 19-20, https://www.ifac.org/system/files/news/files/2011-03-cpa-ireland-accountancyplus-accounting-for-sustainabilitystathis-gould.pdf,

Gümrah, A. ve Büyükipekçi, S. (2019). Türkiye'de Sürdürülebilirlik Raporlaması: 2008-2017 Yı1ları Arası Yayınlanmış Sürdürülebilirlik Raporlarının İncelenmesi. Muhasebe Bilim Dünyası Dergisi, 21 (2), 305-323.

Karadeniz, E. ve Uzpak, B.D. (2019). Dünyada En Yüksek Marka Değerine Sahip Otel Zincirlerinin Sürdürülebilirlik Faaliyetlerinin Küresel Raporlama Girişimi İlkeleri Bağlamında İncelenmesi. Seyahat ve Otel İşletmeciliği Dergisi, 16 (1), 6-20.

Karadeniz, E. ve Uzpak, B.D. (2020). Borsa İstanbul konaklama Şirketlerinde Sürdürülebilirlik Faaliyetlerinin Analizi. Seyahat ve Otel İşletmeciliği Dergisi, 17 (2), 288-310.

Özçelik, F. (2018). Çevre Muhasebesi, Dora Basım Yayın, Bursa.

Özerhan, Y. ve Sultanoğlu, B. (2018). Sürdürülebilirlik Raporu Kapsamında Çevresel Bilgilerin Raporlanması ve Güvence Denetimi. Muhasebe ve Denetime Bakış, (53), 55-76.

Sak, A.F. ve Dalgar, H. (2020). Kurumsal Sürdürülebilirliğin Firmaların Finansal Performansına Etkisi: BIST Kurumsal Sürdürülebilirlik Endeksindeki Firmalar Üzerine Bir Araştırma. Muhasebe ve Finansman Dergisi, (85), 173-186.

Süklüm, N. ve Hiçyorulmaz, E. (2019). BİST Sürdürülebilirlik Endeksindeki İşletmelerin Sosyal Sorumluluk ve Çevre Muhasebesi İlişkisi Açısından İncelenmesi: Bir İçerik Analizi. Business \& Management Studies: An International Journal 7 (4), 1806-1824

Şendurur, U. ve Temelli, F. (2018). Türkiye'de Faaliyet Gösteren Geleneksel Bankalar ve Katılım Bankalarının Sürdürülebilirlik Açısından Karşılaştırılması. Muhasebe Bilim Dünyası Dergisi, 20 (2), 330-346.

www.globalreporting.org/how-to-use-the-gri-standards/gri-standards-english-language/, Erişim Tarihi: 08.03.2021.

Yeşilçelebi, G. (2020). Türkiye'de Faaliyet Gösteren Bağımsız Denetim Kuruluşlarının Sürdürülebilirlik Açılamaları: Sürdürülebilirlik raporlarının içerik analizi. Gümüşhane Üniversitesi Sosyal Bilimler Enstitüsü Elektronik Dergisi, 11 (Ek), 229-244.

Yılmaz, E. ve Bayrak Oğuz, R. (2020). Türkiye'deki Konaklama İşletmelerine Ait Sürdürülebilirlik Raporlarının GRI Raporlama Standartlarıyla Karşılaştırmalı Analizi. Journal of Social and Humanities Sciences Research, 7 (54), 1381-1405. 